\title{
Library and Information Science education: look beyond library and information services
}

\author{
Dr. H.S.Siddamallaiah \\ Principal Librarian and Information Officer \\ NIMHANS- Deemed University, Bangalore- 560029 \\ sidda@nimhans.kar.nic.in
}

And

\section{Dr.C.R.Karisiddappa}

Professor and Chairman, Dept of Lib \& Inf. Sc.

Dean, Faculty of Social Sciences, Karnatak University, Dharwad - 580003

e-mail: Karisiddappa@gmail.com

\begin{abstract}
Development of librarianship, though has good theoretical support, is not emulated to the sciences and art of knowledge society. Librarianship, as a profession, emanated through accumulation of ideas from various professionals entities. However due to the varied needs of the users, technological application, derivation of information activity in various fields like "information management" "knowledge Management" "information engineering" and "Information sciences", development of librarianship as information science was left behind. This study concentrates on "how librarianship is to be developed into a science. The science of librarianship is somehow lagging behind both at academic and research activity, whereas in practice level, information science is recognized more as a skill due to lack of on par endorsement from academic and research activity and the relationship of industry (practicing library) and Library and Information Science (LIS) departments.
\end{abstract}

Keywords: Library education, South Asia, Library and Information Services

\section{Introduction}

Librarianship is a science "behind information consolidation and beyond information service" such as collection development, organization, disseminating tools, librarianusers interaction and service. Librarianship as a transaction is like a bank wherein mobilization of information resources is like cash and retrieval of information is like transaction. In LIS education, concentration is more towards "how the library" than "how the science of librarianship" not in compliance with the versatile demand of the job market for librarians due to lack of industry- university partnership (to be market- based 
or market oriented approach). It is a well established fact that the education has to be reflective to practice and the theoretical knowledge at the university cannot create librarians for particular operating situations. It has been realized that librarians learning on the job or during acclimatization to the given working environment are dominated by user-centered services not just resources-centered. To bridge the gap between theory and practice, LIS education requires three component viz. a) core knowledge of library science, b) application of IT and c) a knowledge of organization behavior and management including domain knowledge of the host organization. Each student is unique in their interest and learning. To provide fair chance to students to concentrate more on their interested subject, it would be more suitable to implement Choice Based Credit System (CBCS). Job market for librarians is moving towards specialty and superspecialty approach in packaging information with respect to domain knowledge. Experimentation on specialization is exceptionally slow and in super-specialty it is absent. Majority of the courses in India and in many other developing countries are concentrating more on traditional library positions with IT application ignoring a long list of other information careers.

\section{Rationale}

LIS professionals needs to accomplish their aim of the development, deployment, and management of information resources and services both in print and electronic media. They are to be prepared for information-based solutions in all contexts of the society, and to provide the competitive edge for the knowledge-based organization. At the same time, information resources are considered as intellectual capital in the global context. The role to be played by the LIS professionals is:

- To deal with both internal and external information resources for innovation and continuing learning.

- To gain control over ever-increasing amounts of information in multiple storage formats.

- To solve the problem of information overload which require good understanding of domain knowledge of the host organization for using suitable filters of information.

- To become in using suitable tools, technology and logistics for information organization, analysis and packaging it for user service

- To be good in skills like communication, value addition and flexible and positive attitude towards ever changing environment.

\section{Competencies in modern librarianship}

The core competencies for LIS professionals are like mobilizing/sharing of knowledge and creating a roadmap of growth and development of library as a part of host organization. These competencies can be strengthened by the knowledge of products, services and policies in line with the values and principles of the profession and host organization. The core competencies in line with the profession are: 
- Management of operational and financial resources in making decisions and strategic considerations.

- Judicious implementation based on information applications, tools and technologies, and policies for the organization.

- Concentrating on professional and personal development within the information organization.

- Marketing of information services and products, formally and informally, through web and physical communication collateral, presentations, publications and conversations.

- Gathering the best available evidence to support decisions about the development of new service and products, the modification of current services or the elimination of services to continually improve the array of information services offered

- Advising the organization on copyright and intellectual property issues and compliance.

- Developing suitable policies for mobilizing, organization and dissemination of information resources.

- Identifying, selecting, evaluating, securing and providing access to pertinent information resources in any media or format recognize the importance of users including the ability to critically evaluate, select and filter them.

- Organizing, categorizing, cataloguing, classifying, disseminating; creating and managing taxonomies, intranet and extranet content, thesauri etc including deployment of access tools.

- Negotiating the purchase and licensing of needed information products and services.

- Designing, developing, testing, marketing, packaging and delivery in an integrated approach as applied particularly institutions supported by sound policies.

- Identifying and use of appropriate current technology and tools to deliver or provide access to quality resources for teaching, research and practice of users.

- Identifying good databases, indexing and metadata including analysis and synthesis of information.

- Deriving proper information literacy or users training about various products, services and tools including emerging technology and effective use of information service/products (client and content-centered approach).

- Information retrieval, interpretation, synthesis, product development and virtual services on a global scale.

\section{Competencies for participating in intellectual society}

The changes in academia and research activities in various other fields demands on-par improvement of expertise from the professionals in the respective field. At the same time the IT professionals are devising many automatic tools and technique, as a userfriendly technological solution for users to access and download needed information on their own. The researchers think that Internet search engines (touches the surface of the needed knowledge) can locate the Web Site and incidentally some relevant information, when the database of scientific literature are more suitable for searching and accessing comprehensive information with the help of librarians in preparing search strategy. However the science and expertise of librarians are yet to be recognized as a 
value for academia and research including community information service. It is high time, having good tools and techniques, to develop the service integrated to academia and research.

Academicians, researchers and citizens are working as pressure groups to transform libraries and creating new demands, wherein LIS education has to be pro-active in deriving and updating the curriculum on par with demands of the users. The teaching and learning in LIS education is still confined more to core knowledge and IT skills through traditional classroom-centered approach. On the contrary, librarians all over the world are emphatically supporting the library-centered life long education considering the transformation from traditional to virtual. The development of science or knowledge is striding more towards interdisciplinary than uni-disciplinary approach. The curriculum and course development including continuing education have taken an interdepartmental or inter-institutional approach keeping global perspectives in view.

The emergence of the knowledge economy and the commoditization of knowledge is driving librarians to learn and honour varied sources of knowledge-bases including traditional and in-house generated knowledge. In mobilization of all kinds of information resources librarians are expected to work as pathfinders by assisting all learners with varied backgrounds and abilities through information supportive environment and multiple strategies. The critical thinking and research-based practice for knowledge mobilization is more essential in the present context. Knowledge resources consolidation and organization, particularly in a virtual environment, expect librarians to support various education programs, liaison role within knowledge, creating supportive environment for learners and strengthen relationship between learners and teachers/guides. The development of integrated information environment into curriculum using faculty collaboration has to have built-in opportunities for success and transferability of information and also usage skills from context to context and to profession for different styles for learning (traditional knowledge to professional knowledge).

\section{Instability and Demand}

The development of user friendly digital environment emanated a feeling that why should there be a separate profession for librarianship? and why not educate every body in accessing and using information, when everything is user friendly in technology environment?. In the context of this question, following are few options we can look into;

- Join hands and develop it as a multidisciplinary science;

- Develop LIS in its own aspects as dominating content using digital technology as a tool and

- If digital technology is the dominating content, keeping the cognitive aspects and interaction with users (front end of the service) to blend legacy system upgraded to the digital technology.

Of course library professionals have to compete with technologists in providing customized solution for information service. There are various subjects dealing with information activity such as "information management" or "knowledge management" in business studies, updating their expertise with relevant concepts from library and 
information sciences and applying it in corporate culture and blending the expertise creating new customized professionals to suits today's environment. The computer science or digital technology professional subject have realized the need of content management and creating new breed of professionals "information sciences". Information activity as practice is integrated to all walks of society. Looking at the global competition, which is treading towards "information superpower" the science of librarianship, is gaining more importance "as a profession" and also in practice. To achieve higher order professionalism, the expertise and LIS education should be proactive and oriented to on-par changes with technology, expectations of the society and global competition.

\section{Integration to academic activity}

The user's attitude towards accessing and usability of information in digital environment has changed remarkably. The IT application and integration of information service has changed the perception of the people about information landscape in academia, research, consumer education and public in using information for solving their problems in their day-to-day activity, In fact "Timely information is money and timely information is solution". The digital environment has emanated varied information products, media and formats, where users find it very difficult in searching; accessing and downloading information. These difficulties have made user to depend more on technical library staff. The library professional has derived academic materials for creating awareness and training users about information landscape, searching including usability of information. Many professionals are arguing that it is high time that "information literacy training" should become a compulsory subject at college level in all the courses at bachelor and masters degree to make them life long learners. In the education system information science as knowledge is integral part of everybody's life. Information is a capital and information science is an open bank, libraries are social institution or Commoners University.

Librarians have been working, since many decades, with thorough knowledge of assessing the user's needs and learner's needs in addition to identified key faculty members. In an e-learning environment, experienced/ acclimatized users in digital environment are demanding for integration of information to learner's assignments, curricula for the year including suggestions of faculty on required references for all assignments. The enrichment of information sources and effective retrieval can be achieved by working with faculty during curriculum revision and informal conversations. Faculty knows their curriculum and the librarian's knows their resources, the exercise will be bringing together learners and resources/facilities.

\section{Information society}

The demand in academia is "learn to learn", wherein major portion is access to customized knowledge such as learn to use information, learn to assess quality of information, and learn to integrate information in all intellectual activity/ environment. It is well established fact that the intellectual society is dominated by information component. In a broad sense it is high time to think of many aspects like; how to create intellectual society or informed society? In borderless society which already in vogue through mass 
media or Internet (society). The LIS education has greater responsibility in information and Internet society. The traditional librarianship has created unidirectional expertise to maintain library and help users to locate/access to information, wherein technological component is added as tool. The LIS education has incorporated technology in its expertise to use it successfully. However it is essential to study science of application and think, what expertise to be strengthened and what expertise to be depleted?

Information component is taught in various other professional fields like in engineering "information engineering" whereas library/information science field is confined to "engineering information", in business environment "knowledge management" whereas library/information professionals are confined to "information for business environment or business information system", Information in industrial environment as "industrial information" whereas librarians confined to information for industrial system. All these factors clearly shows that librarians always think of their core sciences as applied to the targeted environment not as an "integrated subject" considering it as specialization or super-specialization. Hence the growth and scope of the library and information sciences has never been identified as the integrated core science in any of the fields. Librarians are always recognized as a peripheral service component. Never was it recognized as either allied sciences of any field or core subject which can be applied to all other field though the scope and need is very wide. LIS education surely has many different requirements and qualifications like study of information in the context of targeted field to come out with specialization. The additional skills expected from the librarians are communication skill, information analysis, inter-operability, interpretation and application of information technology.

\section{Need for specialization}

The specialty in LIS education is experimented more on user groups, government libraries, institution-based libraries (academic or research) or corporate libraries. There is a need to equip next generation professional to be familiar with specialized future trends. To raise the standard and status of the LIS professionals, it is essential to develop their mind set to work as information solution providers not just an "information provider from the existing resources". In India many LIS professionals are working in corporate sectors providing information solutions for day-in and day-out decision making as chief information officer or knowledge officer. The expertise of library science professionals in information analysis and consolidation, repackaging of information, preparation of technical digest are very supportive for business information particularly for collection, collation, consolidation and re-packaging information to the context.

LIS education to a little extent is covering media publishing industry including development, management, processing and selling of information. New breed of LIS professionals are participating in special subjects like e-publishing, press agencies, multimedia market, bookstores, archives and customized information services. Therefore, the coming generation of information professionals, in digital environment, are expected to undertake tasks of knowledge management (from business information systems based on published information), of in-house information, consumer health information system to public health services, clinical librarianship to Evidence based medical librarianship, software library to coding library and so on. These developments are 
forcing academicians to have partnerships with relevant practicing librarians and watch closely for changes and take advantage of anything that gives an opportunity to evolve further. The education of librarians is inseparable from the vision of the library of the future and the changing roles and skills of this professional community.

\section{Change in Legacy system}

The management of libraries and information service as a culture has many changes like outsourcing additional work, establishments, collaboration with technology department, joint projects to develop or repackage information, working out cost effectiveness and collection development. The trend changed from managing personal (face-to-face) service to virtual service (asynchronous), yet subject librarians need to provide special services to users interested in specific areas of knowledge in virtual mode. The librarians are continuing to work in "user-centric approach" even in virtual access systems which in-fact moved from acquiring information to provide access to information. The effectiveness of cost savings and the process of library co-operation are more effective, particularly at purchase mechanism called consortia (virtual purchase club) across the border of the country or region.

Many of the users have realized that internet provides free and unfiltered access to junk information than scientific information and it is not a substitute for libraries. Also it is felt that developing Information repositories at institutional level and archiving them is an asset, for which majority of the institutions are depending on librarians for the job. Actual need of the librarians in digital environment is more for mobilizing, filtering, customized access including authentication of information resources.

The transformation of libraries is not migrating from traditional media to digital in total, but it is the process of evolving hybrid libraries. The new generation librarians need to have base knowledge (which is good science in its own value) of classification, cataloguing, indexing, thesaurus development, reference logics and users education. It has to be simulated with the IT environment and the expectations of new generation and of course on par demand with the Information society.

\section{Librarians in digital society}

Sequential learning skills in this society are fading away and lateral approach to learning is becoming popular. Librarians are required to move from generalist approach to specialist approach. Almost all the professionals are dividing their skills in different components such as;

- Core expertise

- Soft skills

- Management skills

- Technology skills

- Cultural skills

- Specialist skills

It is the working and communication ability that has to be enhanced along with teaching and analytical skills in different contexts, and creativity in subject environment 
is the specialization required for advancement and enhancement of the subject. These skills enable librarians to build innovative and research abilities. The librarian's knowledge and familiarity with the decision support system enable them to dominate in business and trading society. LIS Professional of the next generation is going to be a finer blend of core knowledge of library sciences, technology application and domain knowledge of the organization or subject of the host organization.

The information technology application is different at different level of work and size of the library or information service. If librarians are expected to learn every thing about IT like operating systems, programming languages, graphical design software and web design in addition to content management and database systems, it needs total reorientation at Bachelors Degree level or selection of candidates for entry in to the programmes themselves. If this is the requirement, LIS professionals have to obtain qualifications of B.Sc., B.E., or BCA in computer science or computer application or computer engineering after the LIS qualifications. Computer science graduates have their own field in today's development. If they are interested in joining tLIS programmes, the social and economic returns for the job varies, otherwise library and information science has to be merged with IT field. In fact approach for content management and dissemination needs a different culture than IT culture or IT as a science.

IT professionals are not oriented to classification of ideas, analysis and synthesis of information and repackaging, development of products, users counseling and supporting research/ academic activity. There has always been a debate on incremental customization of expertise in working environment to train people for lateral entry to higher-level post. The nature of work at entry-level post of library and information services in big libraries is different from one-person library/information or head of the library as a department.

The academic role of librarians has many negative and positive arguments all over the world. The knowledge on use of information systems, use of technologies, usability of information, knowledge on how to acquire knowledge, is helpful for life long learners. In school libraries, consolidating and providing access-learning objects involve the evaluation of the content itself.

\section{Skill attributes}

The skill-based jobs are expected to apply the skills to a particular job or an environment, whereas the professional job involves planning, development, and initiation of new services or to emulate the professional knowledge in any setting up of the system or subject to enhance the capability of the users. The professional jobs have sound theory and science of its own to apply at multiple environments like management principles.

Librarians play more than just administering the libraries in bringing together the information and the right users based on their skills even in information management (IM) or Management Information System/ Service (MIS) or Knowledge Management (KM). In context of IM, MIS or KM, there is a need for analysis and consolidation inhouse and organizational information with respect to objectives of the host organization including prediction management. Librarians are good in analysis and consolidation of information as skills wherein domain knowledge has to be built as culture than as a 
science. The knowledge of working environment or knowledge of organization is part and parcel of every professional, may need mentoring. In the same way, a good librarian needs to be mentored into positions with considerable accomplishment in their parent institutions and organizations, if placed under the right circumstances. The interactions with users (user's pressure) shape the attitude as well as the development them to work for their environment for those who right background knowledge.

The education and working environment with continuing education support for an individual having positive spirit creates able, effective and efficient librarians. The conglomeration of skills and competencies of some individual with right basic degree (mostly relevant to domain knowledge of the host organization) with library qualification create a good match for the successful attainment proportionate to the expectation of an organization. The life-long education in consonance with the professional practice in information industry and desire to move ahead is an built in process for librarians or information workers.

Librarians being a learning system supporter with relevant, tailor made information service it becomes important to decide what to learn or understanding the direction of personal, professional growth one should choose in context of technology and users service. The speed of growth of literature in various media and changing expectation of users with respect their exposure/ changing projects or research subjects, librarians has to tune their learning activities represent a major problem.

The role of librarians in a broader perspectives move beyond the training obtained at formal courses. Professional participation, working environment, working with management and users of information for meeting the learning and research needs drives the librarian's culture in context of position leveled in the organization. The identification, capture, organization, storage, retrieval, analysis, interpretation, packaging, and dissemination of information are the core knowledge irrespective of the organization or level in which a professional librarian is working. Each of these activities, as core knowledge of library and information sciences looks different at application, if one does not understand these concepts in context of execution. Execution is a culture as well as learning.

Information work/ librarianship, or specialist librarianship, or records and information management, or archives management, or information brokerage, or publishing. The information service for learning, research or corporate culture target focused services, unlike public libraries (broader approach), whereas specialist librarian or corporate librarian integrate information to knowledge work of parent organizations. The information professional is not guided just by framework of professional education; it also should match to new information management environment and host institution. The development of information management usually is driven by working environment and domain knowledge. Like software professionals, the activity and the knowledge of librarians is linked to the domain knowledge of the working environment. Software professionals work for software object, librarian's works on information/ learning objects. This approach is emanating single new profession, customized to the service and crosses all boundaries information domain and applications. Of course it has the critical "link," to the attainment and establishment for the new profession. The recognition and the identity is first element to be established to go for unified approach to specialty and super-specialty approach. 
Developing activity-wide standards of quality and excellence, in education for admission into the field, need to keep the demand and supply for performance practices, careers and disciplines, branches of information services that contribute to the larger profession thereby form a new information management profession.

Information professionals with their recognition of legacy system are to be changed both in mindset, applications and qualities of a plan along with the elevation of self esteem of librarians in new direction with certain characteristics and attributes that are in their conception ( in under developing and developing countries) and in their execution (in developed countries). Perhaps these ideas of information management profession result in selecting and ensuring the best practice and recognized for the qualifications intended for the new development.

\section{Conclusion}

The focus of librarianship, in practice, from collection development to simulating users need, is confined more as skill with expanded development of information retrieval tools. The librarianship is practiced like application software and tools than development of theory (science) behind the services. This emulation calls for on par development in LIS education as "information science". Even the identity and image of librarians is assumed as an active role in assisting researchers in their research process, than professional research support system. Earlier, librarians used to routinely assist patrons in choosing an appropriate topic of research (hot topic), information mapping and searching information resource as part of most reference interactions, without much of IT support. After IT application, the expertise is developed more as skill "specialized search skills" and knowledge of the workings with specific databases. The effective professionalism in this context need to be enhanced with required expertise to the librarians in deriving the correct evidence support, for effective relationships between librarians and researchers. Of late databases and the search engines are developed with more sophisticated approach wherein librarians are to concentrate more on training users. In this context, librarians need to be a good teacher and consolidator of research support system with "information literacy skill", which has to incorporated in curriculum of LIS education. The role of the librarians in virtual environment via web links to the library website is becoming the actual needs for providing access to suitable information sources calls for "web designing capability" including hyper linking to the full text or to the documentary centers. 